\title{
The Accounting Educators' Perceptions of Integrated Reporting
}

\author{
Elizabeth Sugiarto D. ${ }^{1^{*}}$, Estralita Trisnawati ${ }^{1}$, M. F. Djeni Indrajati ${ }^{1}$ \\ ${ }^{1}$ Faculty of Economics and Business, Universitas Tarumanagara, Jakarta, Indonesia \\ ${ }^{*}$ Corresponding author. Email: elizabethsugiarto@fe.untar.ac.id
}

\begin{abstract}
Given the large number of financial and non-reporting information of financial services that are presented today, Integrated Reporting (IR) is seen as a solution to users for decision makings. This research was conducted descriptively in investigating the accounting educators' perceptions of integrated reporting. The specific purpose of this research is to describe the opportunities \& benefits as well as the challenges \& disadvantages of integrated reporting in the accounting educators' points of view. This research used SPSS version 20 for data analysis purpose based on the data from 49 accounting educators in 2020. The results of this study illustrate the accounting educators' perceptions of the implementation of integrated reporting, which shows that there are significant differences between the Average Opportunities and Benefits (AVEPM) and Challenges \& Disadvantages (AVETK). The conclusion is that the Average Opportunities and Benefits of integrated reporting implementation (AVEPM) is greater than the Average Challenges and Disadvantages of integrated reporting implementation (AVETK).
\end{abstract}

Keywords: Accounting Educators' Perceptions, Integrated Reporting

\section{INTRODUCTION}

Unerman (2011) in [10] asserted that the development must not sacrifice the survival of future generations, therefore entities must have a long-term thinking strategy. On the other hand, the financial statements that are presented are getting thicker, more and more information must be read by stakeholders so that it can confuse the readers. Therefore, the International Integrated Reporting Council (IIRC), that is supported by business people and investors from more than 25 countries and several international standard setting institutions including representatives of the IASB, IFAC, and GRI, compile the integrated reporting standards (Integrated Reporting). Integrated reporting is concise communication that is integrated related to the strategy, governance and remuneration, performance and prospects of an organization in generating short, medium, and long-term value. It also focuses on how the entity creates sustainable future value that benefits all stakeholders overtime.

Accounting Educators, as the agents who promote integrated reporting knowledge, need to draw their own perceptions of integrated reporting so that their position can be seen whether the majority of accounting educators support or do not support the application of integrated reporting. The perceptions of accounting educators can determine the material that is socialized to students, which in the end can be delivered to public as the users of integrated reporting and to companies as integrated reporting presenters.

The formulation of the problems in this study are (1) Does financial reporting confuse users, because it is considered to be overloaded with information? (2) Does each financial reporting have weaknesses in providing information? (3) Does the development of technology encourage companies to accelerate the provision of information that users must feel? (4) Does the company worry about providing transparent information due to hypercompetition? (5) Do users always want to know in full the fundamental data of the companies they invest in ? and (6) Is there a significant difference between opportunities \& benefits as well as challenges \& disadvantages of integrated reporting implementation? This research was conducted descriptively to investigate the accounting educators' perceptions of integrated reporting. Thus, the specific purpose of this study is to describe the opportunities and benefits as well as the challenges and disadvantages of integrated reporting.

\section{LITERATURE REVIEW}

IAI [10] explains the guiding principles underlying the preparation of integrated reporting, how it informs the contents of the report, and how the information is presented, namely: a. focus on strategy and future orientation; b. information connectivity; c. connected stakeholders; d. materiality; e. brevity; f. validity and reliability; and g. consistency and comparability. The agency theory assumes that both investors and managers (agents) are rational parties and have their respective interests so that they will try to maximize their own interests. The manager as an agent does not always act in 
accordance with what is expected by the investor so that it can cause agency problems which ultimately lead to agency costs that ultimately must be borne by investors. Anojan [1] examined the perceptions of accounting experts such as academics, auditors, professional accountants (Chief Financial Officers), graduates majoring in accounting, accounting undergraduate students, and accounting-profession students in the implementation of integrated reporting in Sri Lanka. The research questionnaire was divided into two parts: (1) opportunities and benefits, and (2) challenges and disadvantages, in the application of integrated reporting. The descriptive results based on SPSS output show that the average opportunity and benefits of implementing integrated reporting are higher than the average challenges and disadvantages. It was further stated that there was a lack of knowledge and awareness of integrated reporting in Sri Lanka. Respondents recommend an integrated reporting training program for internal and external stakeholders.

Adhariani and Villiers [2] found there was limited knowledge regarding the integrated reporting, but the level of importance was high. Lipunga [13] presented the results of his study that the average Integrated Reporting Index (IRI) suggests making some progress towards integrated reporting (IR) by companies and, on the other hand, the integrated reporting gap (IR) shows the need for more efforts to be made in promoting integrated reporting (IR) among companies registered in Malawi. Dumay et al [6] suggested the results of their research that the lack of flexibility and the details of actual and metric disclosures in integrated reporting allows it to be used for compliance, apart from other benefits voiced by IIRC.

Neynar et al [17] suggested that there is a perception gap, because the company does not fully understand the information that is valuable to stakeholders. Stubbs et al [21] shows that all respondents agreed that there were problems in the company's current reporting regime, but it was still questionable whether the integrated reporting could be a solution by continuing to encourage companies to report on environmental and social sustainability risks. Moolman et al [14] shows that most companies comply with the disclosure requirements listed in the international framework (IIRC 2013b) related to risks and opportunities, except for the disclosure of certain risk assessments, and stated that the integrated reporting had led to limited changes in risk and opportunity disclosure. Orobia [18] presented the results which show that companies are slow to adopt the integrated reporting due to resources, culture and leadership, stakeholder requests, regulatory requirements, globalization effects, and mindset, which is lack of the awareness about integrated reporting, and the nature and size of business. Goicoechea et al [7] expressed the perceptions of auditors and users of audit reports about the aspects of integrated reporting assurance that is considered important, but with many challenges (both methodological and related to the characteristics of nonfinancial information). Bhasin [3] found that at present there is no universally-accepted global framework for integrated reporting and most practices are still voluntary and they believe that integrated reporting of financial and nonfinancial performance must be compulsory, and must become a universal practice for all companies listed globally in the next 5-10 years.

Steyn [20] revealed the results of his study that in a mandated regulatory regime implemented in a short period with reference to a highly prescriptive draft framework, attaching value to the Integrated Reporting process primarily came from the perspective of their corporate reputation, investor needs, and stakeholder engagements and relations. Sofian and Dumitru [19] supported the use of tools to measure the compliance of integrated reports with the existing requirements in an industrial context related to many other domains.

Nazier and Umiyati [16] revealed that the implementation of integrated reporting in Indonesia still requires hard work from internal and external parties, and tends to increase costs with uncertain benefits. The results of Kustiani's study [12] illustrate that on average companies listed in the Stock Exchange in general have met 50\% of the elements needed and have voluntarily reported the information needed, both financial information and nonfinancial information about corporate social and environmental obligations, so that if the Financial Services Authority requires the presentation of integrated reporting in the near future, companies listed in the the Indonesia Stock Exchange (IDX) will not be difficult to fulfill. Chariri and Januarti [4] stated that companies listed in IDX have presented annual reports in accordance with the elements of integrated reporting even though the area of presentation is low, amounting to $51 \%$ (33 of 64 indicators), and concluded that audit committee expertise (in accounting / finance) and the frequency of audit committee meetings has a positive effect on the scope of integrated reporting. In line with Indonesia, in Malaysia the results of the MIA-ACCA Integrated Reporting survey revealed that the integrated reporting knowledge was relatively low. Meanwhile, it also revealed that only 13\% had in-depth knowledge of integrated reporting. It was also revealed that the integrated reporting was a potential solution to help financial markets operate effectively by supporting long-term value creation by considering various capital and creating short, medium, and long-term values.

Hoque [9] argued that many stakeholders cannot use the information disclosed because of the separation of reports, therefore the integrated reporting combines financial and non- financial measures into one report. Joshi [11] argued that the corporate financial reporting has developed rapidly due to the increasing demand of stakeholders for transparent and non-financial information. Cosma et al [5] found that the stock market reacts positively to the announcement of awards, the value attributed by shareholders to IR quality remains growing over time and very high among non-financial companies. Haji and Hossain [8] concluded that the emerging IR practices and multiple capital frameworks have not really improved the substance of the organization's report. 


\section{HYPOTHESIS DEVELOPMENT}

This study uses primary data by distributing questionnaires to accounting educators to illustrate their perceptions of integrated reporting of go-public companies in the IDX. The accounting educators' perceptions of Integrated Reporting are measured about the opportunities and benefits as well as the challenges and disadvantages of the implementation of integrated reporting. Referring to the Theory of Planned Behavior, it is expected that respondents who have a perception of Integrated Reporting will have a higher-rate of benefits and opportunities than that of the challenges and disadvantages of its implementation. Therefore, the hypothesis in this study was developed as follow:

$\mathrm{H}_{1}$ : There is a significant difference between the 'benefits and opportunities' and the 'challenges and disadvantages' of integrated reporting.

\section{RESEARCH METHOD}

The population in this study are all accounting educators in Jakarta and Tangerang Cities. The sampling method in this research was convenience sampling by taking the samples from accounting educators in Jakarta and Tangerang, especially at Universitas Tarumanagara, STIE Trisakti, Universitas Kristen Krida Wacana, and Universitas Pelita Harapan. Data was collected by questionnaire that was distributed through Google Form during the first semester of 2020. The questionnaire used was obtained from previous research conducted by Anojan [1]. This research variable is related to (1) The opportunities and benefits of integrated reporting implementation, and (2) The challenges and disadvantages of integrated reporting implementation. Both of these variables were revealed from the questionnaire responses regarding the implementation of integrated reporting. Data processing was done by using SPSS version 20 with descriptive analysis.

The problem formulation items ranging from 1 to 5 will be described from the questionnaire responses. The result of normality test shows that the data was normally distributed. And to answer the problem formulation in point $6 \mathrm{a}$, the hypothesis testing method used a paired $\mathrm{t}-$ test.

\section{RESULTS AND DISCUSSIONS}

The result of this study is consistent with Anojan [1] showing that the average opportunity and benefits of implementing the integrated reporting is higher than the average challenges and disadvantages. This result revealed the first problem that among 49 respondents in general, as much as $65.3 \%$ understood the financial reporting by stating that Financial Reporting did not confuse users, while the remaining $34.7 \%$ stated that Financial Reporting confused users because of being overloaded with information. Based on this description, it can be revealed that most of the perceptions of accounting educators on Financial Reporting will be more concise and does not make users more confused. On the other hand there are still $34.7 \%$ of respondents who had not received a complete picture of financial reporting so they felt that financial reporting would confuse the users. This requires a wider dissemination of integrated reporting implementation so that the level of knowledge of accounting educators can better to understand and is expected to encourage stakeholders to be more open in facing the free competition. This condition is in line with the finding of Adhariani and Villiers [2] , which stated that there is limited knowledge regarding the integrated reporting in Southeast Asia and the lack of requests from stakeholders for integrated reporting. Meanwhile, Lipunga [13], who conducted the integrated reporting studies in developing countries, needed more efforts in promoting the integrated reporting among listed companies. Likewise, Dumay et al [6] revealed that the many integrated reporting methods pose theoretical and empirical challenges for academics in relation to their socialization.

The second problem was answered by $95.9 \%$ respondents who mentioned that each financial statement has a weakness in providing information. Based on the answers of these respondents, it can be revealed that the majority of accounting educators agree that each financial report has a weakness in providing information. Those weaknesses in financial statements are related to their semantic meaning that have long been described in various accounting theory books. Although there is a view that the choice of accounting methods cannot do a lot in beautifying the financial statements, this has become one of the concerns of the users of financial statements. This condition is in line with the finding of Neymar et al [17] which stated that there are gaps in stakeholder perceptions as a result of the type of disclosure and the way the financial statements are presented so that integrated reporting is needed. Likewise, this is similar to Stubbs et al [21], who stated that all research respondents agreed that there were problems in the company's current reporting regime and there was a gap between the information provided by companies and the information needed by capital providers for investment decisions, so the integrated reporting is expected to have the potential to bridge this gap.

Revealing third problem, all respondents agreed that the technological development encourages companies to accelerate the provision of information that users must feel about the benefits. This reveals that the era of technological development must be utilized as an information dissemination tool that helps accountants convey the information to users. This is in line with the finding of Moolman et al [15], which stated that the integrated reporting provides new insights for companies and stakeholders that drive the change toward integrated thinking between strategy, risk, and opportunity. Orobia [18] revealed that companies are slow to adopt the integrated reporting because of resources, culture, and leadership, stakeholder request, regulatory requirements, 
globalization effects, and the mindset, that is lack of awareness about integrated reporting and the nature and size of the business, so this can hamper the implementation of integrated reporting even though it has been supported by the development of sophisticated technology. Likewise, Goicoechea et al [7] expressed the perceptions of auditors and users of audit reports that integrated reports are important but still have many challenges, both in terms of methodology and characteristics of non-financial information. Bhasin [3] also revealed that there is no universally-accepted global framework for integrated reporting and most practices are voluntary, and therefore must be mandatory and become a universal practice for all companies that will go public in the next 5-10 years. In line with this, Steyn [20] suggested that it needs to be understood that the development of sophisticated information technology is perceived to help accelerate the provision of information and even enhance the reputation of the company, but it will not be able to replace the profession of accountant and auditor, because the rules of the information presented need to be agreed between the accounting professionals, companies, and the users of financial statements. Sofian and Dumitru [19] concluded that it is necessary to use a tool to measure the compliance of integrated reports with the existing requirements in an industrial context related to many other domains, so that technology can be used as a tool.

Revealing the fourth problem, $73.5 \%$ of respondents said that the company was worried about providing transparent information because of hypercompetition, while the remaining $26.5 \%$ said that the company was not worried about providing transparent information. This reveals that there is still considerable concern on transparency even from the perceptions of accounting educators who should be able to understand the benefits of transparency in providing the information. Nazier and Umiyati [16] suggested that companies are beginning to realize the need to incorporate all aspects of sustainability reporting and financial reports in a single report called integrated reports, although in Indonesia it still requires hard work from internal and external parties, and tends to add uncertain costs and benefits. Kustiani [12] revealed that, in average, companies listed in IDX in general have met $50 \%$ of the required elements and have voluntarily reported financial and non-financial information about corporate social and environmental obligations needed for decision making. In line with this, Chariri and Januarti [4] also revealed that the companies listed in IDX have presented annual reports in accordance with the integrated reporting element even though only $51 \%$ are the indicators (33 out of 64 indicators). Likewise, MIA-ACCA [14] revealed that integrated reporting knowledge was relatively low, of which as much as $51 \%$ of the 330 respondents said that they did not know about the integrated reporting and only $13 \%$ had in-depth knowledge of integrated reporting. Thus the accounting educators should support the transparency without worrying about the era of hypercompetition, because transparency shows the existence of the company as it is in the public opinion and it becomes an opportunity to attract investors who like honesty or the right presentation. Revealing the fifth problem, $93.9 \%$ users always want to know in full about the fundamental data of the companies they invest in. This shows that the accounting educators still consider the users to need complete fundamental information as a basis for decision making. Therefore, the information must be made as whole, concise, and as transparent as possible so that the presenter can be more appreciated by the users. It was also stated by Hoque [9] that stakeholders find it difficult to use the information disclosed, because it requires integrated reporting that unites the financial and non-financial measures in one report. In line with this, Joshi [11] also suggested that the company's financial reporting has grown rapidly, because it increased the stakeholders' demand for transparent and non-financial information. Cosma et al [5] also stated their findings that the stock market reacted positively to the announcement of awards, and the value was attributed by shareholders to the quality of integrated reporting. This shows that the users really want to know all the information that exist in the company, both financial and non-financial information, that has an impact on the company's going concern, which is not only what has been in the financial statement notes. In line with this phenomenon, Haji \& Hossain [8] revealed that the corporate reporting is increasingly in accordance with the integrated reporting language.

Based on the normality test result, the data was considered normally distributed. Therefore, the paired sample t-test shows the value of 0.000 (less than 0.05 ), thus $\mathrm{H}_{1}$ was accepted. So, it can be concluded that there is a significant difference between the opportunities and benefits (AVE PM) and the challenges and disadvantages (AVETK) of integrated reporting. It also revealed that respondents already have an adequate understanding of the opportunities and benefits as well as the challenges and disadvantages of implementing the integrated reporting. The basis of understanding the integrated reporting among accounting educators already exists, it only needs to be disseminated more broadly so that this understanding can spread to investors and management. Investors, as capital providers who invest their funds in companies, always want to know the information in full. Management as capital manager is responsible for reporting the company's performance to investors. The agency problems often arise, if the management's interests differ from those of investors. Asymmetric information, whereas investors often get less information than expected, and management tends to only inform good news information, very often creates the agency costs, which ultimately must be borne by investors. This can actually be bridged with the transparency which reveals the existence of the whole company that is expected to be presented through the integrated reporting. Therefore, investor and management perceptions must be directed to the intentions determined by attitudes, subjective norms, and correct behavioral control, as expressed in Theory of Planned Behavior (TPB) by Ajzen (1991) in [22].

As stated by Unerman (2011) in [10], company growth must not sacrifice the survival of future generations, so 
long-term strategy must always be widely thought-out and socialized without the fear of being imitated by competitors. Innovation never stops, so in the future companies must always think of strategies with innovations that can attract investors. Competitors, who can only imitate, will not be able to keep up with the next innovation, and will always be left behind.

\section{CONCLUSIONS}

The result of this study indicates the Average Opportunities and Benefits (AVEPM) of the integrated reporting implementation is higher than the Average Challenges and Disadvantages (AVETK) of the integrated reporting implementation. This is consistent with Anojan's finding [1]. The majority respondents $(65,3 \%)$ stated that Financial Reporting did not confuse the users, while the remaining $34.7 \%$ stated that Financial Reporting confuses the users because of being overloaded with information. As much as $95.9 \%$ of respondents suggested that each financial statement has a weakness in providing information related to the semantic meaning. All respondents agreed that the development of technology encourages companies to accelerate the provision of information that users must feel the benefits. This study revealed that $73.5 \%$ of respondents said that the company was worried about providing transparent information due to hypercompetition. As much as $93.9 \%$ of respondents suggested that the users always want to know in full about the fundamental data of the companies they invest. This study revealed that there are significant differences between the average of opportunities and benefits (AVE $\mathrm{PM}$ ) and the average of challenges and disadvantage (AVETK). Integrated reporting is related to a brief description of the company's strategy, governance and remuneration, performance and prospects, that will produce short, medium, and long-term value. Long-term strategies must always be thought-out and socialized without the fear of being copied by competitors. Innovation never stops, competitors who can only imitate will not be able to keep up with the next innovation, and will always be left behind.

The limitations of this study is that this study only revealed about the respondents' perceptions as accounting educators, which only amounted to 49 persons. Therefore, further research is expected to increase the respondents so that they can provide a more complete picture of the implementation of integrated reporting.

Until now, the integrated financial reporting in Indonesia has not been required for companies listed in the IDX. Perception difference between presenters and users should be disclosed so that the presentation of integrated reporting can provide a complete overview of financial and nonfinancial conditions of the company.

\section{ACKNOWLEDGMENTS}

This work was supported by The Institution of Research and Community-Engagement Services (LPPM) of Universitas Tarumanagara. Thus, Authors would like to thank the Director of LPPM and also the Dean of Faculty of Economics and Business - Universitas Tarumanagara, along with all related staffs who cannot be mentioned one by one.

\section{REFERENCES}

[1] Anojan, Vickneswaran (2019); Perception of Accounting Experts on the Implementation of Integrated Reporting in Sri Langka; Global Journal of Management and Business Research: D Accounting and Auditing volume 19 issue 1 version 1.0; Global Journals; Online ISSN:2249-4588, Print ISSN: 09755853.

[2] Adhariani, Desi \& Charl de Villiers; (2018); Integrated Reporting: Perspectives of Corporate Report Prepares and Other Stakeholders; Sustainability Accounting, Management, and Policy Journal; October 2018; https://doi.org/10.1108/ SAMPJ -02-2018-0043.

[3] Bhasin, Madan Lal; (2017); Integrated Reporting: The Future of Corporate Reporting; International Journal of Management and Social Sciences Research (UMSSR) volume 6 no.2, February; www.irjcjournals .org.

[4] Chariri, Anis; Indira Jauarti; (2017); Eksplorasi Elemen Integrated Reporting dalam Annual Reports Perusahaan di Indonesia; Jurnal Akuntansi UNTAR volume XXI no.03, September; pp 411-424; DOI: 10.24912/ja.v21i3.245; E-ISSN: 2549-8800 ISSN: $1410-3591$

[5] Cosma, Simona; Maria Gala Soana; Andrea Venturelli; (2018); Does The Market Reward Integrated Report Quality?; African Journal of Business Management vol 12 (4) pp 78-91, 28 Feb.; DOI: 10.5897/AJBM2017.8469; ISSN: $1993-$ 8233; http://www.academicjournals.org/AJBM

[6] Dumay, John; Cristiana Bernardi; James Guthrie; Matteo La Torre; (2017); Barriers to Implementing the International Integrated Reporting Framework: A Contemporary Academic Perspective; Meditari Accountancy Research; volume 25, issue 4, pp 461480. 
[7] Goicoechea, Estibaliz; Fernando Gomez-Bezares; Jose Vicente Ugarte; (2019); Integrated Reporting Assurance: Perceptions of Auditors and Users in Spain; Sustainability 2019, 11, 713; DOI: 10.3390/su11030713; www.mdpi.com/ journal/sustainability

[8] Haji, Abdifatah Ahmed; Dewan Mahboob Hosain; (2016); Exploring the Implication of Integrated Reporting on Organisational Reporting PracticeEvidence from Highly Regarded Integrated Reporters; Qualitative Research in Accounting \& Management volume 13 no.4 pp415-444; Emerald Group Publishing Limited 1176-6093; DOI 10.1108/QRAM07-2015-0065; www.emeraldinsight.com /1176.6093.htm

[9] Hoque, Mohammad Enamul; (2017); Why Company Should Adopt Integrated Reporting?; International Journal of Economics and Financial Issues volume 7 issue 1, pp 241-248; ISSN:21464138; http://www.econjournals.com

[10] Ikatan Akuntan Indonesia(IAI); (2015); Modul Pelaporan Korporat; Mei; www.iaiglobal .or.id

[11] Joshi, Prem Lal; (2018); Integrated Reporting: Current Trends in Financial Reporting; International Journal of Accounting Research volume 6 issue 2; DOI: 10.4172/2472- 114X.1000177; ISSN:2472$114 \mathrm{X}$

[12] Kustiani, Nur Aisyah; (2017); Penerapan Elemen-Elemen Integrated Reporting pada Perusahaan yang Terdaftar di Bursa Efek Indonesia; May; https://www.researchgate.net/scientificcontributions/2160816954_Nur_Aisyah_Kustiani

[13] Lipunga, Andrew Munthopa; (2015); Integrated Reporting in Developing Countries: Evidence from Malawi; Journal of Management Research vol.7 no.3; ISSN 1941-899X; www.macrothink.org/jmr

[14] Malaysian Institute of Accountants (MIA)ACCA; (2016); Integrated Reporting Survey; https://www.accaglobal.com>MIA-ACCA-IR-surveyreport_2016.pdf

[15] Moolman, Jaco; M. Oberholzer; M. Steyn; (2016) The Effect of Integrated Reporting on Integrated Thinking Between Risk, Opportunity and Strategy and The Disclosure of Risk and Opportunities; Southern African Business Review volume 20.

[16] Nazier, Daeng M; Indah Umiyati; (2015); Dimensia volume 12 no.1 pp 1-34; 1 Maret; http://ejournal.stiesa.ac.id [17] Neynar, Nolin Riley; Asheer Jaywant Ram; Warren Maroun; (2018); Expectation Gap Between Prepares and Stakeholders in Integrated Reporting; Meditari Accountancy Research volume 26 no.2 page 241-262; Emerald Publishing Limited 2049-372X; DOI 10.1108/MEDAR-12-2017-0249

[18] Orobia, Laura; (2019); The Adoption of Integrated Reporting: A Develping Country Perspective; Journal of Financial Reporting and Accounting vo. 17 no.1 pp 2-23; Emerald Publishing Limited 1985-2517; DOI 10.1108/JFRA-09-20170089

[19] Sofian, Ioana; Madalina Dumitru; (2017); The Complience of The Integrated Reports Issued by European Financial Companies with The International Integrated Reporting Framework; Sustainability, 9, 1319; DOI: 10.3390/su9081319; www.mdpi.com /journal/sustainability

[20] Steyn, Maxi; (2014); Organisational Benefits and Implementation Challenges of Mandatory Integrated Reporting - Perspecitves of Senior Executives at South African Listed Companies; Sustainability Accounting, Management and Policy Journal volume 5 no.4, pp 476-503; Emerald Group Publishing Limited 2040-8021; DOI 10.1108/SAMPJ-11- 2013 0052

[21] Stubbs, Wendy; Colin Higgins; Markus Milne; Leslie Hems; (2014); Financial Capital Providers' Perceptions of Integrated Reporting Working Paper; SSRN Electronic Journal; July; DOI:10.2139/ ssrn.2473426; https://www.research gate.net/ publication/264311389

[22] Wahyono, Budi; (2014); Teori Perilaku yang Direncanakan (Theory of Planned Behavior); www.pendidikanekonomi.com 